\title{
Apoptosis of the mammalian retina and lens
}

\author{
David S Papermaster ${ }^{1,2}$ \\ 1 Department of Pathology, University of Texas Health Science Center at San \\ Antonio, San Antonio, Texas 78284-7750; USA \\ tel: 2105674007 fax: 210567 6312; e-mail: papermaster@uthscsa.edu \\ 2 Address after January 1997: Department of Pharmacology, School of Medicine, \\ University of Connecticut Health Center, Farmington, Connecticut, 06030, USA
}

Received 30.8.96; revised 9.9.96; accepted 12.9.96

Edited by H. Steller

\begin{abstract}
Although retinal neurons usually last the entire lifetime of an individual, many innate genetic and developmental errors and external stimuli can reduce their longevity leading to loss of visual acuity or blindness. Similarly, the lens, largely composed of denucleated fiber cells must remain transparent for life if vision is to remain clear. Apoptosis of retinal neurons and newly generated lens fiber cells contributes to retinal degeneration and cataract formation, respectively, in both humans and experimental mammals. The apoptosis is triggered by many stimuli in addition to inherited mutations and may be amenable to pharmacologic amelioration. These studies not only provide new clinical insights but also the opportunity to investigate the molecular pathways leading to apoptosis in an organ that is not required for survival. The eye, becomes, therefore, an important organ for evaluation of theories of apoptosis in vivo.
\end{abstract}

Keywords: apoptosis, cell differentiation, development, gene expression, humans, lens, mice programmed cell death, rats, retina, retinitis pigmentosa

Abbreviations: RP, retinitis pigmentosa; ICE, interleukin-1bconverting enzyme; RPE, retinal pigmented epithelium; FGF, fibroblast growth factor; CNTF, ciliary neurotrophic factor; HPV, human papillomavirus; $\mathrm{pRb}$, retinoblastoma gene product; ts, temperature sensitive

\section{Introduction}

Blindness is profoundly disabling and is widely feared as a consequence. So much of the information of modern society arrives in visual form that loss of sight during youth or in mid-life may greatly restrict social and career opportunities despite the heroic capacities of some affected individuals to extend their effectiveness using other sensory systems. In the elderly, loss of sight is also costly. Since their mobility may be limited, blindness compromises reading and use of television and computers to entertain and to obtain information besides losing a vital component of sociability.
Biopsy of the human eye is rarely performed. There is therefore a serious paucity of information about the development of the pathologic lesions of the retina in most blinding disorders. Occassional glimpses of partially damaged retinas early in the course of a retinal degeneration appear when death occurs from another disease or accident. Often, the degeneration affects the structure or longevity of rods and/or cones, the primary photo-responsive sensory cells in the retina. It is also becoming clear, however, that degeneration of other cells in the retina, especially ganglion cells, may be compromised by early onset of cell death. Ganglion cells are third-order retinal neurons whose axons project to the central nervous system through the optic nerve and become damaged in glaucoma.

Most retinal degenerations in humans destroy neurons slowly. Sensitive tests may detect onset of degeneration in early childhood, but most patients experience significant functional loss in the second decade of life or beyond (Berson, 1993). Loss of rods results in a reduced visual field culminating in tunnel vision and night blindness. Loss of cones, on the other hand, leads to profound loss of visual acuity since these cells cluster in the center of the human retina and subserve high-resolution vision in bright light.

Ophthalmologists employ non-invasive electrophysiological mapping of the responsiveness of the retina using light spots on dark or on illuminated backgrounds (mapping rod and cone functions, respectively). They also measure the magnitude and rate of response to a flash (latency) and rate of response to a flickering light (additional ways to distinguish rod and cone functions) to determine the extent of functional loss. These measurements all provide important clinical clues about which cells, rods, cones or both, are affected and can be used to estimate the progression of disease in longitudinal studies. Some inherited retinal degenerations are collectively termed retinitis pigmentosa (RP), a reflection of the altered distribution of black pigmented epithelial cells in the back of the diseased retina.

Many inherited disorders leading to premature death of retinal neurons are encoded by a diverse set of mutations on nearly every human chromosome (Bird, 1995). Despite important molecular genetic studies that have contributed to an exact description of the mutations in some of these disorders, the clinical complexity continues to confound simple cause-effect reasoning because a single mutation may induce a diversity of clinical features in a kindred (Dryja and Berson, 1995). Generations may be skipped, siblings may have diseases with striking variation in functional loss of vision and different 'diseases' appear to track within one family. Can these be explained by a process resembling the observation of 'weak' mutations in Drosophila? (see Bonini, this issue).

Thus, while the mutations are a necessary condition for the disease to arise, they are an insufficient basis for 
clinical classification or description of the pathogenesis of these diseases. (Papermaster, 1995). Indeed, some mutations affect genes whose expression is widespread on many other tissues, yet the primary clinical effect is in the retina or elsewhere in the visual system (Johns et al, 1993; Jun et al, 1994; Neuman, 1993; Seabra et al, 1992, $1993,1995)$. This clinical dilemma in disorders of the visual system is shared by other degenerative disorders elsewhere in the nervous system including the spinal cord and central nervous system such as amyotrophic lateral sclerosis and Alzheimer's disease.

With the discovery that apoptosis describes the premature death of retinal neurons in a variety of settings (Chang et al, 1993; Lolley et al, 1994; Papermaster and Nir, 1994; Portera-Cailliau et al, 1994; Tso et al, 1994) the stage was set for an assault on the mechanism of death regardless of its initiating cause. Initial studies involved mice affected by well described mutations of genes primarily or exclusively expressed in photoreceptors and a strain of rats whose photoreceptors died secondarily because of defects in an adjacent pigmented epithelial cell layer. Further studies of ischemia-reperfusion (Buchi, 1992a,b), light damage, retinal detachment (Chang et al, 1995) and toxic exposure to lead (Fox et al, 1996) and other agents (Nakajima et al, 1996) have broadened the scope of this field of research and revealed issues that are now the subject of lively investigation. This review will summarize these recent studies to illustrate the diverse stimuli that initiate apoptosis in retinal neurons and some early attempts to ameliorate the effects by pharmacologic or genetic means. Other recent reviews offer emphasis on other aspects of the problem (Adler, 1996; Gregory and Bird, 1995; Steinberg, 1994).

\section{Apoptotic death of rod and cone photoreceptors in inherited retinal degeneration in humans, mice and rats}

The normal development of the mammalian brain requires apoptotic death of a significant fraction of newly generated neurons. The retina, an 'accessible piece of brain', is no exception. The retina differentiates from a primitive layer of ventricular cells (Figure 1). As each cell type becomes specified, Young (1984) and Penfold and Provis (1986) found waves of cell death in the three retinal layers simply by counting the number of pyknotic nuclei at various ages. Of course, at the time of these pioneering studies, little was known about apoptosis and few criteria were available to distinguish from other forms of cell death. Since the duration of persistence of the pyknotic nuclei was also unknown, the rates of birth and death were impossible to establish even in $\left[{ }^{3} \mathrm{H}\right]$-thymidine labeled retinas.

As additional criteria became available it was possible to re-evaluate the earlier studies, seeking phagocytes of dead cells by adjacent neurons or macrophages and localizing apoptotic bodies by electron microscopy, measuring DNA cleavage by electrophoresis in agarose and employing

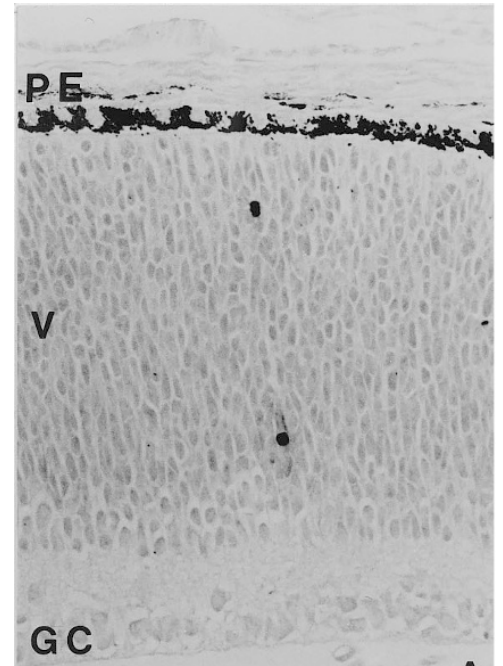

A
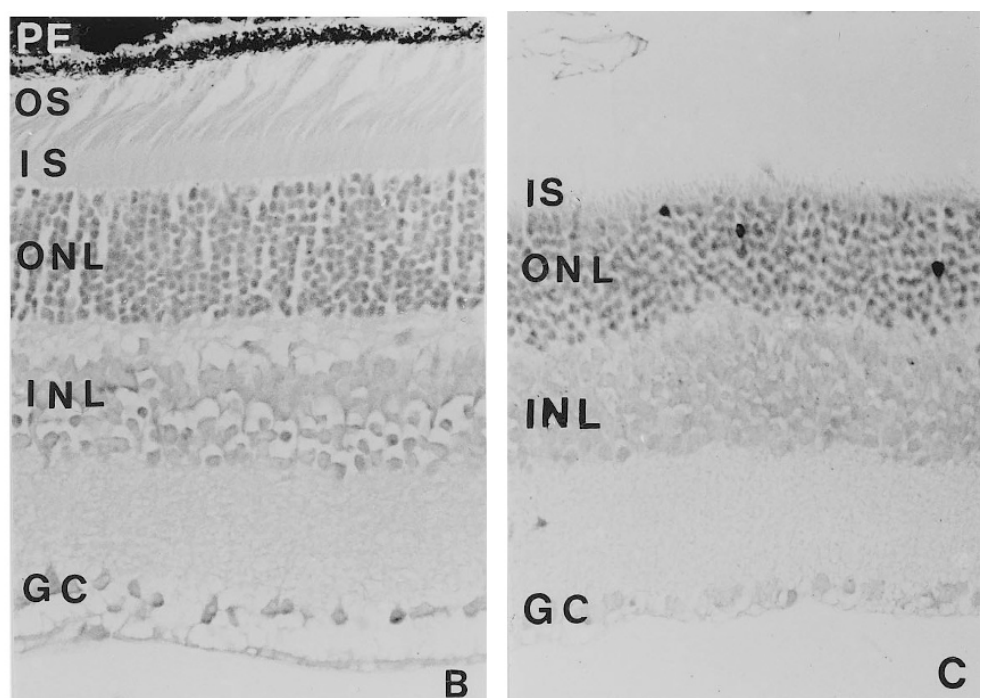

Figure 1 Light micrographs of a 4 day old and 28 day old BALB/c retina illustrating the maturation of the retina from a thick ventricular layer of undifferentiated photoreceptor and interneuronal precursors at 4 days to a tri-laminar retina at 28 day old. For comparison, a rds mouse retina illustrates the continued death of photoreceptors in the adult with this inherited retinal degeneration. (A) 4 day old normal mouse retina. Rare scattered apoptotic nuclei and nuclear fragments are distributed at low density throughout the ventricular layer (V) reflecting the apoptosis during development of this immature retina. Maturing ganglion cells (GC) have already separated from the precursors of the other layers. Pigmented epithelial (PE) cells abut the neural retina. (B) In a 28 day old normal adult retina no labeled nuclei are seen. At most, 1-2 nuclei are labeled in the entire retinal section of an adult retina. Rod and cone inner segments (IS) and outer segments (OS) are formed by the photoreceptors in this normal retina. The photoreceptor nuclei reside in the outer nuclear layer (ONL) and interneurons (amacrine, horizontal and bipolar cells) lie in the inner nuclear layer (INL). (C) rds retina at 28 days. These mice cannot form outer segments because of a mutation of the peripherin/rds gene (Connell et al, 1991; Travis et al, 1989). The outer nuclear layer (ONL) and inner segment layer (IS) contain several apoptotic nuclei in this adult mutant retina. TUNEL assay by the procedure of Gavrieli et al (1992). Counterstained by methyl-green. $\times 280$. 
various in-situ labeling techniques (Figure 1). Independent studies of cell death in the retina all lead to the same conclusion: apoptosis is a 'final common pathway' of death of photoreceptor cells in mature retinas that are perturbed either by certain mutations (Chang et al, 1993) or by a variety of exogenous external stimuli, e.g, excessive light, hypoxia or lead. (Buchi, 1992a,b; Chang et al, 1995; Cook et al, 1995; Fox et al, 1996; LaVail et al, 1992; Shainfar et al, 1991). The rates of loss of photoreceptor nuclei are easily determined by counting surviving nuclei at each age. Comparison of these assessments with the labeling density of apoptotic nuclei by the TUNEL assay (Gavrieli et al, 1992) indicates that adjacent cells eliminate apoptotic photoreceptor nuclei rather slowly (ca. 12-24 h) compared with other tissues (ca. $30 \mathrm{~min}$ ) (Papermaster and Nir, 1994).

These findings alter the interpretation of many clinical studies of inherited retinal degeneration. A form of ADRP was localized to chromosome 3 (McWilliam et al, 1989); since the rhodospin gene mapped to the same region, Dryja et al (1990) soon found a mutation that was linked to the clinical disease. Subsequently over 70 mutations of the rhodospin gene and of several other genes that participate in photoreceptor function or structure have been described. (Berson, 1993; Bird 1995; Dryja and Berson, 1995).

Even the first family found to have a Pro-23-His mutation of rhodopsin presented problems of interpretation, however. Not only did the proband lose rod function but she also lost cone vision in her macula that cost her high visual acuity. Since rhodospin is only expressed in rods and not in cones, one could ask why should cones die if they don't express the mutant gene? The older sister of the proband was asymptomatic and yet she carries the mutation and has a significant loss of rod function and a partial loss of cone function. She simply didn't notice the loss because she used lights at night to drive her truck and dependend on her surviving central and peripheral cones. Classically, geneticists explain this phenotypic variation by the term 'incomplete penetrance', a subject I recently reviewed (Papermaster, 1995).

Why are one sister's cones partially preserved while her younger sister is blinded by the same mutation? With respect to cone survival, is this disease recessive or semidominant in the sister with preserved cone function while it is dominant in her totally blind younger sister? Is cell death of rods and cones cell-autonomous (intrinsic, independent) or dependent on the health of adjacent photoreceptors? Recent studies of tetraparental mice generated from a chimera of normal and transgenic blastulae bearing a mutated transgenic opsin gene reveal that rods bearing the mutation die in the mosaic retina and injure the adjacent normal photoreceptors (Huang et al, 1993). The numbers of dying normal photoreceptors is proportional to the fraction of the retina occupied by mutant rods. Yet the survival of cones in one sister of the affected kindred described above indicates that the mechanisms of injury expressed in this experimental system cannot be straightforwardly extrapolated to the clinical disease in humans. Clearly the clinical classification of retinal degeneration is incomplete using the limited functional and genetic criteria available.
Invoking the concept of incomplete penetrance is relatively straightforward when the genotypes of the individuals are as different as two sisters. Even developmental differences may be invoked to 'explain' differences in penetrance in identical twins. But recent studies of another rhodospin mutation, Thr-17-Met, has stressed this concept to its logical limit. In most individuals carrying this mutation, the retinal degeneration is not widely distributed over the entire retina but is largely confined to the ventral half and usually also destroys the cone-rich central retina, the fovea. The upper retinal rods survive and function so that the affected individuals can maneuver around objects on the floor (since the eye inverts the visual image) but they cannot see objected overhead. Can we invoke incomplete penetrance in a tissue? Not only was the retina of a 68 year old man with this mutation subjected to this assault, but his son also has the earlier stages of the same regional (altitudinal) degeneration. Studies of the father's retina at post mortem have directly provided the first evidence for apoptosis in the human retina near the boundary of dying and preserved photoreceptors in the upper retina (Li et al, 1994, 1995).

The impact of this finding is that the rod photoreceptors carrying this rhodopsin mutation can clearly survive for seven or more decades if apoptosis can somehow be prevented, in this case by some regional variation in survival factor(s) in the top half retina affected by a Thr-17Met mutation of rhodopsin. Hay et al $(1994,1995)$ recently demonstrated the validity of this concept by preventing apoptosis of Drosophila retinas and lens cells induced by expression of the reaper gene in the eye with the Baculovirus gene p35. p35 may act by blocking members of the ICE gene family that is a part of a common pathway of apoptosis from worms to man (see review by Clem et al, 1996).

Are there similar anti-apoptotic genes, factors, developmental differences or other mechanisms in humans that preserve half a retina by inhibition of apoptosis? Could these somehow be engineered to function throughout the entire retinal surface? Stimulated by the heterogeneity of the disease in patients, these questions are dominating this new era of study of inherited blinding disorders. The research at all levels of animal life and in all tissues, including their tumors, becomes directly applicable to the study of the dying retina. Conversely, advances in antiapoptosis therapy of inherited retinal disorders should provide suitable leads for studies of inhibition of apoptosis throughout the nervous system to prevent or at least ameliorate these devastating diseases. Current studies in mice, rats, cats, chickens and dogs with inherited retinal degenerations seek to evaluate mechanisms of apoptosis and its potential amelioration by the pharmacologic administration of 'survival' factors.

RCS rats, whose rods die secondarily by apoptosis in response to a mutation that affects the adjacent cell layer, the retinal pigmented epithelium (RPE) have been one object of study. The mutant rat RPE cells fail to phagocytose and digest the debris generated each day by the continual renewal and formation of new rod disk membranes and shedding of old disks in the normal eye. 
The retinas die by apoptosis (Papermaster and Nir, 1994; Tso et al, 1994); injections of a variety of factors including $\alpha \mathrm{FGF}$ and $\beta \mathrm{FGF}$ delay the rate of degeneration (Faktorovich et al, 1990). Preliminary reports, however, indicate that the RCS rat expresses normal levels of immunocytochemically dectable $\beta$ FGF before the onset of degeneration (Naka et al, 1993). Thus, the response to exogenous $\beta$ FGF may reflect a photoreceptor layer that is less vulnerable after elevation of $\beta$ FGF. Alternatively, there may be a problem in release and/or uptake of the factor in addition to the primary mutation of phagocytic function of the RPE cells. A recent report showed that a single interaction of ciliary neurotrophic factor (CNTF) into the vitreous cavity around the time of onset of cell death reduces rod loss in rd mice with a rapid rod and cone death and in transgenic mice expressing a mutant opsin gene that generates a slower degeneration (LaVail et al, 1996). These are important first steps in attempting to develop a pharmacologic approach to inhibition of retinal apoptosis (Steinberg, 1995).

\section{Apoptosis of the retina induced by ischemia-reperfusion, lead and excess light}

Initially, ischemia was expected to induce necrosis with its sequellae of cell swelling, dissolution of organelles and plasma membranes, cell rupture and inflammatory response. Subjecting retinas to varying periods of interruption of blood flow and subsequent restoration, however, generates death of the photoreceptors displaying all the hallmarks of apoptosis (Buchi, 1992a,b). Flunarizine, an intracellular calcium overload blocker, partially protects against ischemic neuronal cell death. The same drug also reduces photoreceptor cell death in light induced retinal degeneration (Takahashi et al, 1992). Treatment with aurintricarboxylic acid also reduces the degeneration (Lam et al, 1995). To the extent that this agent acts on the $\mathrm{Ca}^{2+}-\mathrm{Mg}^{2+}$-sensitive endonuclease that cleaves between nucleosomes, it is unclear why such an agent, acting late in the apoptotic pathway, would preserve these cells in vivo much as it prevents apoptosis in cell cultures in vitro.

Retinal detachment is a common clinical problem, especially in severely myopic humans with elongated eyes. Sudden head trauma also may induce retinal detachment. The retina must be reattached within $24 \mathrm{~h}$ or the photoreceptors will die. In both humans and cats, retinal detachment induces apoptosis of photoreceptors (Chang et al, 1995; Cook et al, 1995). The exact mechanism of injury to the photoreceptors is unclear, but separation of the photoreceptors from the RPE diminishes their access to survival factors that may be generated by these layers of the retina and to oxygen that is delivered by the choriocapillary circulation.

Toxic metal injury also kills rat retinal cells by apoptosis. After exposure of pregnant rats to lead in the drinking water, the pups are born with a disordered retina that shows all the morphologic features of apoptosis. Curiously, agarose electrophoresis does not reveal the typical DNA 'ladder' of small internucleosomally cleaved DNA. Pulsefield electrophoresis shows that the early cleavage of DNA between super-coiled domains generates fragments that are multiples of $50,000 \mathrm{bp}$. Thus a second well-characterized endonuclease is acting on larger stretches of DNA while the $\mathrm{Ca}^{2+}-\mathrm{Mg}^{2+}$-sensitive endonuclease that cleaves between nucleosomes apparently is inhibited by lead (Fox et al, 1996). A single injection of $n$-methyl nitrosourea also induces retinal apoptosis (Nakajima et al, 1996).

Prolonged exposure to bright light induces rapid retinal degeneration in albino rats and only in a few, but not all, strains of albino mice suggesting that the susceptibility is not linked simply to albinsim. Injection of a variety of neurotrophins and other survival factors inhibits cell death to a varying extent, especially in albino rats (Faktorovich et al, 1992). Inhibition of protein synthesis, another characteristic of some forms of apoptotic cell death, decreases the extent of photoreceptor cell loss induced by light damage (Shahinfar et al, 1991).

\section{Viral genes and the genes of cell cycle progression and development and apoptosis of the retina and lens}

In many rodent tissues, transfection of the SV40 T antigen gene (SV40 TAg) results in a loss of control of cell proliferation and transformation to a tumor. Thus it was fully expected that the expression of this gene in the retina would generate a tumor of photoreceptor precursors, a retinoblastoma. SV40 TAg binds to several cellular proteins that participate in regulation of the cell cycle, especially the retinoblastoma susceptibility gene product $\mathrm{pRb}$. This protein appears to control entry into the $\mathrm{G} 1$ phase of the cell cycle. A tumor suppressor gene product, p53, functionally resides at the boundary of $\mathrm{G} 1$ and $S$ phases. The SV40 TAg, adenovirus E1A and E1B55 proteins and human papillomavirus (HPV) E7 and E6 gene products all appear to interfere with the cell cycle regulation in a large part by their impact on either pRb or p53 and the downstream effectors they regulate to induce tumor formation (Nevins, 1992). Surprisingly, after expression of some viral oncogenes in the lens or retinas of the transgenic mice the opposite outcome is observed. Retinal expression of SV40 TAg under the control of the opsin promoter leads to rapid destruction of the photoreceptor layer shortly after birth, when photoreceptors are normally postmitotic and terminally differentiated. Primary cultures of opsin-SV40 TAg transgenic retinas before the death of photoreceptor precursor cells shows that these cells can proliferate in culture (Al-Ubaidi et al, 1992). Thus the in vivo environment is permissive for the development of apoptosis of cells that can otherwise survive in vitro. The SV40 transgene can be expressed before or just after the last division of the photoreceptor cells by use of the interstitial retinol binding protein (IRBP) promoter, which is normally turned on after 13-16 days of gestation in mice. This leads to the formation of retinoblastomas in the retina and pineal (Figure 2, Howes et al, 1994a). These studies both used the full-length SV40 TAg sequence that binds both $\mathrm{pRb}$ and $\mathrm{p} 53$. 
Earlier studies of rat primary fibroblast cells in culture revealed that the apoptosis induced by several viral oncoproteins that bind to $\mathrm{pRb}$ could be blocked by loss of functional p53 or by use of a temperature sensitive (ts) mutant of p53. The cells formed tumor foci at elevated temperature and died at the lower temperature at which tsp53 regained activity. This demonstrated an important role of p53 in regulating cell growth and apoptosis after inappropriate entry into the cell cycle (Debbas and White, 1993).

This model was tested in vivo in the eye by several groups who obtained, at first glance, discordant results. A transgenic HPV E7 gene or a truncated SV40 TAg that only binds pRb but not p53 can be placed under the control of the $\alpha$-crystallin promoter. This largely restricts the effect of the transgene to the lens in a transgenic mouse eye. These mice rapidly develop cataracts because of inappropriate proliferation and apoptosis of lens fiber cells. Fiber cell apoptosis declines significantly in $\alpha$-crystallin-E7 or -truncated SV40 TAg mice if their normal p53 function is inhibited by crossing them with an $\alpha$-crystallin-E6 mouse or by breeding them to be p53 null (Fromm and Overbeek, 1996; Pan and Griep, 1994). Sometimes, a lenticular tumor develops in the double-transgenic mice, a tumor not seen in either transgenic mouse alone. Analysis of embryonic eyes reveals that the apoptosis is highly dependent on the action of p53 only at the early stages of development. Only a few days later, by 17.5 days of gestation, apoptosis is both p53-dependent and -independent (Pan and Griep, 1995).

Using a different promoter, IRBP-HPV E7 transgenic mice develop apoptosis not only of the retina but also of the lens (Figure 2, Howes et al, 1994b). There is, however, only a slight slowing of the rate and no reduction of the final extent of apoptosis of both the retina or the lens in IRBPE7/p53 null mice indicating that E7 inactivation of pRB and its homologues to induce apoptosis might be somewhat p53 independent in this circumstance (Papermaster et al, 1995). This finding is consonant with the observation of both p53-dependent and -independent apoptosis of thymocytes in p53 null mice (Clarke et al, 1993).

Studies of embryonic development of Rb/p53 double null mice also revealed some important additional insights. $\mathrm{Rb}$ null mice die in utero after 13 to 15 days of gestation with widespread failure of hematopoesis, disordered development of the brain and cataracts because of apoptosis of abnormally proliferating fiber cells (Clarke et al, 1992; Jacks et al, 1992; Lee, 1992). Rb/p53 double null mice also die at the same embryonic age yet they have less apoptosis of lens fiber cells when compared to $\mathrm{Rb}$
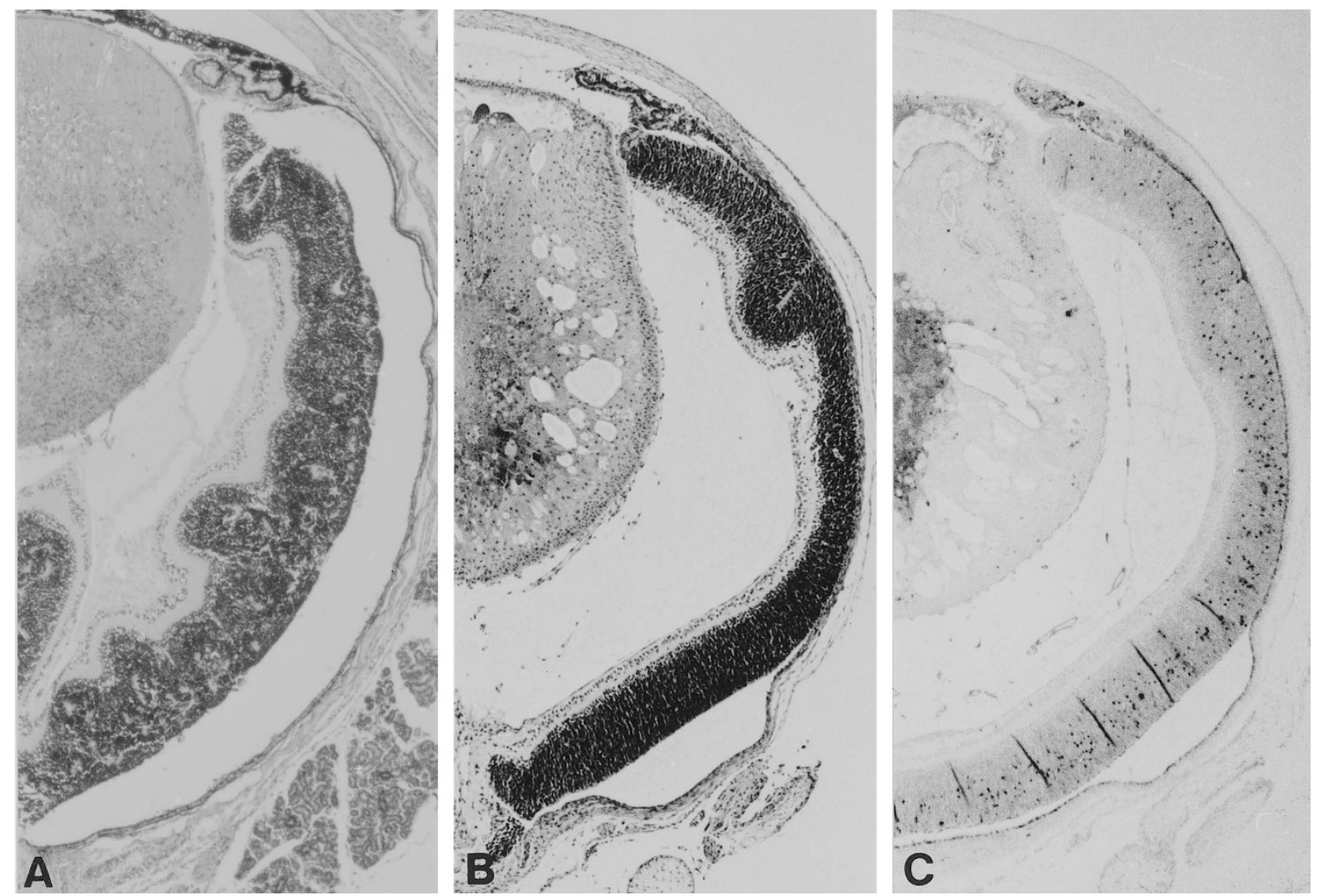

Figure 2 Retinas of IRBP-SV40 TAg and IRBP-E7 transgenic mice. (A) IRBP-SV40 TAg mouse at post natal day 10.5. A tumor of small oval cells, some forming rosettes, obliterates the entire retinal photoreceptor layer. Note the formation of vacuoles and abnormally proliferating fiber cells in the lens. (H\&E stain, $\times 30$ ). (B) IRBPE7 mouse at post-natal day 4. The retinal ventricular layer has separated from the ganglion cell layer of the retina. The lens is vacuolated and dying cells fill its center. $(H \& E$ stain, $\times 50)$. (C) Adjacent section of IRBP-E7 retina and lens at post-natal day 4. Apoptotic cells are widely scattered throughout the retinal ventricular layer. Apoptotic cells are also detected in the fiber cells of the lens. (TUNEL assay, counterstained by methyl-green, $\times 50$ ) (modified from Papermaster et al, 1995, with permission). 
null embryos (Morganbesser et al, 1994). Dissecting out the details of the cell cycle in this tissue has further emphasized the role of pRb and p53 (Fromm and Overbeek, 1996). These results illustrate the importance of p53 in regulating disordered proliferation especially during early stages of this tissue's differentiation (see also, Lang, this issue). Since proliferation and differentiation of the lens and retina proceed normally in p53 null mice, however, apoptosis of these tissues during development is obviously p53 independent (Donhower et al, 1992; Jacks et al, 1994).

An interesting outcome of crossing IRBP-E7 transgenic mice to p53 null mice is the development of retinoblastomas in several mice after one or more months. While apoptosis or malignancy initially appeared to be an 'alternative fate' of the E7 affected photoreceptor with the outcome controlled by the presence or absence of p53, (Howes et al, 1994b) further studies show that nearly all the photoreceptors die by one month so that the tumors arise within a retina that has lost nearly all the precusor cells that should be the cells of origin of the tumor (Papermaster et al, 1995). The sources of the tumors in these retinas are still under investigation using BrdU incorporation to locate foci of tumor stem cell precursors. The apoptosis induced by these viral oncoproteins is provocative and highlight the role of regulation of the cell cycle in apoptosis of the retina and lens. It also illustrates that the intrinsic developmental stage of maturation of the cells at the time of onset of expression of the transgenes is an important contributor to the outcome of the interaction of these terminally differentiating neurons with the oncogenes.

\section{Attempts to modify retinal apoptosis with transgenes that might affect a major genetic pathway of apoptosis. Studies with bcl-2 and $b c l-x L$ under the control of the opsin or IRBP promoter}

Since elevation of expression of $b c l-2$ blocks apoptosis in many tissues in humans and mice, and even partially rescues apoptotic cells in $C$. elegans that bear a loss-of-function mutation of ced-9 (Hengartner and Horvitz, 1994), it was important to determine if $b c /-2$ could rescue a retina destined to die by apoptosis. Chen et al (1996) made transgenic mice bearing a mutated opsin gene that induces an apoptotic degeneration of photoreceptors and crossed them to other transgenic mice expressing $b c /-2$ under the control of a murine opsin promoter fragment. This cross results in partial and temporary preservation of the rods and cones expressing high levels of bcl-2. The bcl-2 transgene also reduces photoreceptor cell loss both in albino mice exposed to 14 days of constant light and in $r d$ mutants. Curiously, they also found that excessive expression of transgenic bcl-2 in normal mice decreases rod and cone survival, perhaps by altering the balance of heterodimers such as Bcl-2/Bax. Overexpression of blc-2 in the retina did not preserve rods and cones of rd mice in a second study (Joseph and Li, 1995).

Preliminary joint studies of transgenic IRBP-bcl-2 and -bcl-xL mice by Windle's and our laboratories have shown abundant expression of each transgene in photoreceptors but no significant reduction in rate or extent of apoptosis of photoreceptors in HPV E7 transgenic mice or in rd mice (Phipps et al, unpublished results). Bcl-2 is not normally expressed at high levels in the retinal photoreceptor but is detectable at higher levels in the inner nuclear layer that contains horizontal, bipolar and amacrine cells. Bcl-xL and bcl-xS are more readily detectable by immunocytochemistry in the photoreceptors. Why overexpression of bcl-2 and bcl$\mathrm{XL}$ is partially effective in one study and is ineffective in others is unclear. These results reveal that more needs to be understood about these important components of the apoptotic pathway and the regulation of their potency as anti-apoptotic agents in the retina.

\section{Conclusions}

The study of apoptosis in the retina and lens is still, obviously, at an early stage. While insights into the pathogenesis of retinal degenerations have been gained in these efforts, the pathways selected to induce apoptosis and their vulnerability to inhibitors remain to be clarified. The use of in vivo systems is clearly a slower experimental approach than studies of cultured cells, but both the normal adult retina and most of the lens fiber cells are post-mitotic and do not lend themselves readily to prolonged culture in the differentiated state. This disadvantage is countered, however, by the availability of relatively tissue-specific promoters that are expressed at early or late stages of differentiation of the tissues and by the potential for study of apoptosis in the native environment since loss of either the lens or retina is not lethal. To the extent that studies of retinal apoptosis also can provide insights into neuronal death in the rest of the central nervous system and spinal cord, they may enhance the capacity to ameliorate not only blinding disorders but other neuronal generations as well.

\section{References}

Adler R (1996) Mechanisms of photoreceptor death in retinal degenerations. From the cell biology of the 1990s to the opthalmology of the 21st century? Arch. Ophthalmol. 114: 79-83

Al-Ubaidi MR, Font RL, Quiambao AB, Keener MJ, Liou GI, Overbeek PA and Baehr W (1992) Bilateral retinal and brain tumors in transgenic mice expressing simian virus 40 large $T$ antigen under control of the human interphotoreceptor retinoidbinding protein promoter. J. Cell Biol. 119: 1681-1687

Berson EL (1993) Retinitis pigmentosa. The Friedenwald Lecture. Invest. Opthalmol. Vis. Sci. 34: 1659-1676

Bird AC (1995) Retinal photoreceptor dystrophies: LI Edward Jackson Memorial Lecture. Am. J. Ophthalmol. 119: 543-562

Buchi ER (1992a) Cell death in the rat retina after a pressure-induced ischaemiareperfusion insult: an electron microscropic study. I. Ganglion cell layer and inner nuclear layer. Exp. Eye Res. 55: 605-613

Buchi ER (1992b) Cell death in rat retina after pressure-induced ischaemiareperfusion insult: electron microscope study. II. Outer nuclear layer. Jap J. Ophthalmol. 36: 62-68

Chang GQ, Hao $Y$ and Wong $F$ (1993) Apoptosis: Final common pathway of photoreceptor death in rd, rds, and rhodopsin mutant mice. Neuron 11:595-605

Chang CJ, Lai WW, Edward DP and Tso MO (1995) Apoptotic photoreceptor cell death after traumatic retinal detachment in humans. Arch. Opthalmol. 113:880886 
Chen J, Flannery JG, LaVail MM, Steinberg RH, Xu J and Simon MI (1996) bcl-2 overexpression reduces apoptotic photoreceptor cell death in three different retinal degenerations. Proc. Nat. Acad. Sci. USA. 93: 7042-7047

Clark AR, Maandag ER, van Roon M, van der Lugt NMT, van der Valk M, Hooper ML, Berns $A$ and te Riele $\mathrm{H}$ (1992) Requirement for a functional Rb-1 gene in murine development. Nature 359: 328-330

Clark AR, Purdie CA, Harrison DJ, Morris RG, Bird CC, Hooper ML and Wyllie AH (1993) Thymocyte apoptosis induced by p53-dependent and independent pathways. Nature 362: 849-852

Clem RJ, Hardwick JM and Miller LK (1996) Anti-apoptotic genes of baculoviruses Cell Death and Differentiation 3: 9-16

Connell G, Bascom R, Molday L, Reid D, Mclnnes RR and Molday RS (1991) Photoreceptor peripherin is the normal product of the gene responsible for retinal degeneration in the rds mouse. Proc. Natl. Acad. Sci. USA. 88: 723-726

Cook B, Lewis GP, Fisher SK and Adler R (1995) Apoptotic photoreceptor degeneration in experimental retinal detachment. Invest. Ophthalmol. Vis. Sci. 36: $990-996$

Debbas $M$ and White $E$ (1993) Wild-type p53 mediates apoptosis by E1A, which is inhibted by E1B. Genes \& Dev. 7: $546-554$

Donehower LA, Harvey M, Slagle BL, McArthur MJ, Montgomery CA Jr, Butel JS and Bradley A (1992) Mice deficient for p53 are developmentally normal but susceptible to spontaneous tumours. Nature 356: 215-220

Dryja TP and Berson EL (1995) Retinitis pigmentosa and allied diseases. Invest Ophthalmol. Vis. Sci. 36: 1197-1200

Dryja TP, McGee TL, Reichel E, Hahn LB, Cowley GS, Yandell DW, Sandberg MA and Berson EL (1990) A point mutation of the rhodospin gene in one form of retinitis pigmentosa. Nature 343: $364-366$

Faktorovich EG, Steinberg RH, Yasumura D, Matthes MT and LaVail MM (1990) Photoreceptor degeneration in inherited retinal dystrophy delayed by basic fibroblast growth factor. Nature 347: 83-86

Faktorovich EG, Steinberg RH, Yasumura D, Matthes MT and LaVail MM (1992) Basic fibroblast growth factor and local injury protect photoreceptors from light damage in the rat. J. Neurosci. 12: 3554-3567

FoxDA, Campbell ML and BlockerYS (1996) Functional alterations and apoptotic cell death in the retina following developmental or adult lead exposure. Neurotoxicity (in press)

Fromm L and Overbeek PA (1996) Regulation of cyclin and cyclin-dependent kinase gene expression during lens differentiation requires the retinoblastoma protein. Oncogene 12: 69-75

Gavrieli Y, Sherman Y and Ben-Sasson S (1992) Identification of programmed cell death in situ via specific labeling of nuclear DNA fragmentation. J. Cell Biol. 119 493-501

Gregory CY and Bird AC (1995) Cell loss in retinal dystrophies by apoptosis - death by informed consent. Br. J. Ophthalmol. 79: 186-190

Hay BA, Wassarman DA and Rubin GM (1995) Drosophila homologs of baculovirus inhibitor of apoptosis proteins function to block cell death. Cell 83: 1253-1262.

Hay BA, Wolff T and Rubin GM (1994) Expression of baculovirus P35 prevents cell death in Drosophila. Development 120: 2121-2129

Hengartner MO and Horvitz HR (1994) Activation of C. elegans cell death protein CED-9 by an amino-acid substitution in a domain conserved in BCL-2. Nature 369: $318-320$

Howes KA, Lasudry JGH, AlbertDM and Windle JJ(1994a) Photoreceptor cell tumors in transgenic mice. Invest. Ophthalmol. Vis. Sci. 35: 342-351

Howes KA, Ransom N, Papermaster DS, Lasudry JGH, Albert DM and Windle JJ (1994b) Apoptosis or retinoblastoma: Alternative fates of photoreceptors expressing the HPV-16E7 gene in the presence or absence of p53. Genes \& Dev. 8: $1300-1310$

Huang PC, Gaitan AE, Hao Y, Petters RM and Wong F (1993) Cellular interactions implicated in the mechanism of photoreceptor degeneration in transgenic mice expressing a mutant rhodopsin gene. Proc. Natl. Acad. Sci. USA. 90: 84848488

Jacks T, Fazeli A, Schmitt EM, Bronson RT, Goodell MA and Weinberg RA (1992) Effects of an Rb mutation in the mouse. Nature 359: 295-300

Jacks T, Remington L, Williams B, SchmittE, Halachmi S, Bronson R and Weinberg R (1994) Tumor spectrum analysis in p53 mutant mice. Curr. Biol. 4: 1-7

Johns DR, Smith KH, Miller NR, Sulewski ME and Bias WB (1993) Identical twins who are discordant for Leber's hereditary optic neuropathy. Arch. Ophthalmol. 111: $1491-1494$
Joseph RM and Li T (1995) Photoreceptor cell death in rd mice may be mediated through a bcl-2 independent pathway. Invest. Ophthalmol. Vis. Sci. 36: S424

Jun AS, Brown MD and Wallace DC (1994) A mitochondrial DNA mutation a nucleotide pair 14459 of the NADH dehydrogenase subunit 6 gene associated with maternally inherited Leber hereditary optic neuropathy and dystonia. Proc. Natl. Acad. Sci. USA. 91:6206-6210

Lam TT, Fu J, Hrynewycz M and Tso MO (1995) The effect of aurintricarboxylic acid, an endonuclease inhibitor, on ischemia/reperfusion damage in rat retina. $J$ Ocular. Pharm. Therapeutics. 11: 253-259

LaVail MM, Yasumura D, Matthes MT, Yanacopoulos GD and Steinberg RH (1992) Multiple growth factors, cytokines, and neurotrophins rescue photoreceptors from the damaging effects of constant light. Proc. Natl. Acad. Sci. USA. 89: $11249-11253$

LaVail MM, Yasumura D, Matthes MT, Lau-Villacorta C, Sung C-H and Steinberg RH (1996) CNTF delays photoreceptor degeneration in $r d$ and Q344ter mutant rhodospin transgenic mice. Invest. Ophthalmol. Vis. Sci. 37: S437

Lee EY, Chang CY, Hu N, Wang YC, Lai CC, Herrup K, Lee WH and Bradley A (1992) Mice deficient for $\mathrm{Rb}$ are nonviable and show defects in neurogenesis and haematopoiesis. Nature 359: 288-294

Li Z-Y, Jacobson SG and Milam AH (1994) Autosomal dominant retinitis pigmentosa caused by the threonine-17-methionine rhodopsin mutation: Retinal histopathology and immunocytochemistry. Exp. Eye Res. 58: 397-408

Li Z-Y and Milam AH (1995) Apoptosis in retinitis pigmentosa. In: Degenerative Diseases of the Retina. Anderson RE, Hollyfield JG and LaVail MM, eds. Plenum Press, N.Y, pp 1-8

Lolley RN, Rong H and Craft CM (1994) Linkage of photoreceptor degeneration by apoptosis with the inherited defect in phototransduction. Invest. Ophthalmol. Vis. Sci. 35: 358-362

McWilliam O, Farrar GJ, Kenna P, Bradley DG, Humphries MM, Sharp EM, McConnell DJ, Lawler M, Sheils D, Ryan C, Stevens K, Daiger SP and Humphries $P$ (1989) Autosomal dominant retinitis pigmentosa (ADRP): Localization of an ADRP gene to the long arm of chromosome 3. Genomics 5: 619-622

Morgenbesser SD, Williams BO, Jacks T and DePinho RA (1994) p53-dependent apoptosis produced by Rb-deficiency in the developing mouse lens. Nature 371 $72-74$

Naka H, Hayashi A, Kuirykama $\mathrm{H}$ and Tang $Y$ (1993) Difference in the postnatal expression of bFGF between RCS and Long Evans rats. Invest. Ophthalmol. Vis. Sci. 34: 1077 Suppl

Nakajima M, Yuge K, Senzaki H, Shikata N, Miki H, Uyama M and Tsubura A (1996) Photoreceptor apoptosis induced by a single systemic administration of $\mathrm{N}$ methyl-N-nitrosourea in the rat retina. Am. J. Path. 148: 631-641

Newman NJ (1993) Leber's hereditary optic neuropathy. New genetic considerations. Arch. Neurol. 50: 540-548

Nevins JR (1992) The E2F transcription factor-a link between the Rb tumo suppressor protein and viral oncoproteins. Science 258: 424-429

Pan Hand Griep AE (1994) Altered cell cycle regulation in the lens of HPB-16E6 or E7 transgenic mice: Implications for tumor suppressor gene function in development. Genes \& Dev. 8: 1285-1299

Pan H and Griep AE (1995) Temporally distinct patterns of p53-dependent and p53independent apoptosis during mouse lens development. Genes \& Dev. 9:2157 2169

Papermaster DS (1995) Necessary but insufficient. Nature-Medicine. 1: 874-875

Papermaster DS, Howes K, Ransom N and Windle JJ (1995) Apoptosis of photoreceptors and lens fiber cells with cataract and multiple tumor formation in the eyes of transgenic mice lacking the p53 gene and expressing the HPV 16 E7 gene under the control of the IRBP promoter. In: Degenerative Diseases of the Retina. Anderson RE, Hollyfield JG and LaVail MM, eds. Plenum Press, N.Y pp. 39-49

Papermaster DS and Nir I (1994) Apoptosis in inherited retinal degenerations. Mihich E and Schimke RH, eds. In Apoptosis, NY: Plenum Press; pp. 15-30

Papermaster DS and Windle JJ (1995) Death at an early age: Apoptosis in inherited retinal degenerations. Invest. Ophthalmol. Vis. Sci. 36: 977-983

Penfold PL and Provis JM (1986) Cell death in the development of the human retina: Phagocytosis of pyknotic and apoptotic bodies by retinal cells. Graefe's Arch Clin. Exp. Ophthalmol. 224: 549

Portera-Cailliau C, Sung C-H, Nathans J and Adler R (1994) Apoptotic photoreceptor cell death in mouse models of retinitis pigmentosa. Proc. Natl. Acad. Sci. USA 91: $974-978$ 
Seabra MC, Brown MS and Goldstein JL (1993) Retinal degeneration in choroideremia: deficiency of rab geranylgeranyl transferase. Science 259: $377-381$

Seabra MC, Brown MS, Slaughter CA, Sudhof TC and Goldstein JL (1992) Purification of component $A$ of Rab geranylgeranyl transferase: possible identity with the choroideremia gene product. Cell 70: 1049-1057

Seabra MC, Ho YKand Anant JS (1995) Deficient geranylgeranylation of Ram/Rab27 in choroideremia. J. Biol. Chem. 270: 24420-24427

Shahinfar S, Edward DP and Tso MOM (1991) A pathologic study of photoreceptor cell death in retinal photic injury.Curr. Eye Res. 10: 47-59

Steinberg RH (1994) Survival factors in retinal degenerations. Curr. Opinion. Neurobiol. 4: 515-524
Takahashi K, Lam TT, Edward DP, Buchi ER and Tso MO (1992) Protective effects of flunarizine on ischemic injury in the rat retina. Arch. Ophthalmol. 110: 862-870

Travis GH, Brennan MB, Danielson PE, Kozak CS and Sutcliffe JG (1989) Identification of a photoreceptor-specific mRNA encoded by the gene responsible for retinal degeneration slow (rds). Nature 338: 70

Tso MO, Zhang C, Abler AS, Chang C-J, Wong F, Chang G-Q and Lam TT (1994) Apoptosis leads to photoreceptor degeneration in inherited retinal dystrophy of RCS rats. Invest. Ophthalmol. Vis. Sci. 35: 2693-2699

Young RW (1984) Cell death during differentiation of the retina in the mouse. J. Comp. Neurol. 229: 362-373 